\title{
Disproportionation of Gold(II) Complexes. A Density Functional Study of Ligand and Solvent Effects
}

\author{
Khaldoon A. Barakat, Thomas R. Cundari,* Hassan Rabâa, ${ }^{\dagger}$ and Mohammad A. Omary \\ Department of Chemistry and Center for Advanced Scientific Computing and Modeling (CASCaM), \\ University of North Texas, P.O. Box 305070, Denton, Texas 76203-5070
}

Received: April 24, 2006; In Final Form: June 6, 2006

\begin{abstract}
A computational study of gold(II) disproportionation is presented for the atomic ion as well as complexes with chloride and neutral ligands. The $\mathrm{Au}^{2+}$ atomic ion is stable to disproportionation, but the barrier is more than halved to $119 \mathrm{kcal} / \mathrm{mol}$ in an aqueous environment vs $283 \mathrm{kcal} / \mathrm{mol}$ in the gas phase. For dissociative disproportionation of chloride complexes, the loss of chlorine, either as an atom $\left(\Delta G_{\mathrm{aq}}=+20 \mathrm{kcal} / \mathrm{mol}\right)$ or as an anion $\left(\Delta G_{\mathrm{aq}}=+15 \mathrm{kcal} / \mathrm{mol}\right)$ represents the largest calculated barrier. The calculated transition state for associative disproportionation is only $9 \mathrm{kcal} / \mathrm{mol}$ above separated $\mathrm{Au}^{\mathrm{II}} \mathrm{Cl}_{3}{ }^{-}$anions. For the disproportionation of $\mathrm{Au}^{\mathrm{II}} \mathrm{L}_{3}$ complexes with neutral ligands, disproportionation is highly endergonic in the gas phase. Calculations imply that for synthesis of a monometallic $\mathrm{Au}^{\mathrm{II}}$ complex, a nonpolar solvent is preferred. With the exception of $\left[\mathrm{Au}(\mathrm{CO})_{3}\right]^{2+}$, disproportionation of $\mathrm{Au}^{\mathrm{II}} \mathrm{L}_{3}$ complexes to $\mathrm{Au} \mathrm{u}^{\mathrm{I}}$ and $\mathrm{Au}^{\mathrm{III}} \mathrm{L}_{3}$ is exergonic in solution phase for the ligands investigated. The driving force is provided by the very favorable solvation free energy of the trivalent gold complex. The solvation free energy contribution to the reaction $\left(\Delta G_{\text {solv }}\right)$ is very large for small and polar ligands such as ammonia and water. Furthermore, calculations imply that choosing ligands that would yield neutral species upon disproportionation may provide an effective route to thwart this decomposition pathway for $\mathrm{Au}^{\mathrm{II}}$ complexes. Likewise, bulkier ligands that yield larger, more weakly solvated complex ions would appear to be desirable.
\end{abstract}

\section{Introduction}

The chemistry of gold is dominated by the chemistry of the monovalent $\left(\mathrm{Au}^{\mathrm{I}}\right)$ and trivalent $\left(\mathrm{Au}^{\mathrm{III}}\right)$ ions. The former tend to be linear, two-coordinate complexes, whereas the latter are typically square planar, four-coordinate complexes. The chemistry of the intermediate formal oxidation state, divalent gold (i.e., $\mathrm{Au}^{\mathrm{II}}$ ), has come under increasing scrutiny in terms of its chemical applications as well as the novelty of this chemical state of gold. Laguna and Laguna have recently published a review of $\mathrm{Au}^{\mathrm{II}}$ chemistry. ${ }^{1}$ The majority of complexes identified as $\mathrm{Au}^{\mathrm{II}}$ in the Cambridge Structural Database and the literature are bimetallic, some with $\mathrm{Au}-\mathrm{Au}$ bonds as short as $2.47 \AA{ }^{2}$ Many binuclear complexes contain phosphorus-ylide ligands, e.g., $\left[\mathrm{IAu}\left(\mathrm{CH}_{2} \mathrm{PMe}_{2} \mathrm{CH}_{2}\right)_{2} \mathrm{AuI}\right]$ and $\left[\mathrm{NCAu}\left(\mathrm{CH}_{2} \mathrm{PPh}_{2} \mathrm{CH}_{2}\right)_{2}-\right.$ AuCN]. ${ }^{1}$ In such cases, the assignment of a bona fide $2+$ oxidation state to gold is not without ambiguity. Even compounds whose stoichiometry imply an $\mathrm{Au}^{\mathrm{II}}$ species, such as " $\mathrm{AuCl}_{2}$ " $\left(\mathrm{Au}_{4} \mathrm{Cl}_{8}\right)$ or $\mathrm{Au}\left(\mathrm{SO}_{3} \mathrm{~F}\right)_{2}$ have been formulated in terms

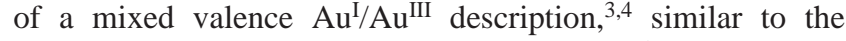
situation known earlier for silver in $\mathrm{AgO} .^{5}$ Hence, such compounds have been termed "pseudogold(II)" by Schmidbaur. ${ }^{6}$ Wieghardt, Neese, and their co-workers have published elegant theoretical-experimental analyses and assignments of dithiolene oxidation states, including "pseudogold(II)" complexes such as $\left[\mathrm{Au}(\mathrm{mnt})_{2}\right]^{2-}$ using a combination of ${ }^{197} \mathrm{Au}$ Mössbauer, UVvis electronic absorption, resonance Raman, and IR spectroscopies in conjunction with density functional theory and time-dependent density functional theory. ${ }^{7}$ In many cases,

* To whom correspondence should be addressed. E-mail: tomc@unt.edu.

$\dagger$ Permanent address: Department of Chemistry, Ibn Tofail University, Kenitra, Morocco. assignments such as $\mathrm{Au}(\mathrm{II})$ are found to be inappropriate as the dithiolene ligands are not fully reduced and are better described as radical anions.

The effect of the chemical environment upon the disproportionation reaction is a worthy topic of consideration. For example, $\mathrm{AuCl}_{2}$ is stable with respect to disproportionation in the gas phase (as determined from DFT calculations by Schröder et al. ${ }^{8}$ and Blackmore et al. $)^{9}$ although solid $\mathrm{AuCl}_{2}$ does disproportionate. ${ }^{3}$ Schwerdtfeger and co-workers have used computational chemistry methods to study a different gold disproportionation reaction, i.e., disproportionation of monovalent gold complexes to elemental gold and trivalent gold complexes. ${ }^{10}$

Monometallic $\mathrm{Au}^{\mathrm{II}}$ complexes are comparatively rare with notable examples including $\left[\mathrm{Au}\left\{\mathrm{S}_{2} \mathrm{C}_{2}(\mathrm{CN})_{2}\right\}_{2}\right]^{2-},{ }^{11}$ other related bis(dithiolato)gold(II) complexes, ${ }^{12,13}$ bis(dicarbollido) gold(II) complexes such as $\left[\mathrm{Au}\left(\mathrm{C}_{2} \mathrm{~B}_{9} \mathrm{H}_{11}\right)_{2}\right]^{2-},{ }^{14}$ and the neutral $\mathrm{Au}(\mathrm{II})$ complex with phthalocyanine. ${ }^{15}$ Although these complexes are paramagnetic, EPR studies suggest that in many cases the unpaired electron resides primarily on the ligands while the spin density on gold is typically only $15 \%, 4,11,16$ thus obscuring assignment of the correct oxidation state of gold. Other examples suggesting a localized unpaired electron on an $\mathrm{Au}^{\mathrm{II}}$ center have been reported, albeit as transient species or impurities. ${ }^{4,17} \mathrm{~A}$ remarkable noble gas complex has also been isolated, formulated as $\left[\mathrm{AuXe}_{4}\right]^{2+}\left(\mathrm{Sb}_{2} \mathrm{~F}_{11}{ }^{-}\right)_{2}{ }^{18}$

El-Sayed ${ }^{19}$ and co-workers studied the chemistry of $\mathrm{Au}^{\mathrm{II}}$ chlorides in connection with their research on the deposition of gold nanoclusters. Stace and co-workers studied the entire series of divalent coinage-metal $\left(\mathrm{Cu}^{\mathrm{II}}, \mathrm{Ag}^{\mathrm{II}}\right.$, and $\left.\mathrm{Au}^{\mathrm{II}}\right)$ complexes in the gas phase with prototypical organic (e.g., acetone and 
2-butanone $)^{20}$ and inorganic (e.g., water and ammonia) ligands. It was concluded, on the basis of mass spectrometric studies, that $\sigma$-donor and $\pi$-acceptor ligands will best stabilize gold in the $2+$ oxidation state, ${ }^{21}$ which is the same conclusion reached earlier by Herring et al. about the electronic factor of the ligands in order to stabilize the formation of a mononuclear Au(II) complex. ${ }^{4}$

In a previous paper from this group,$^{22}$ it was deduced through density functional theory that cationic tris(phosphine)gold(I) complexes undergo a Jahn-Teller distortion from a trigonalplanar toward a T-shaped geometry $\left(\mathrm{P}-\mathrm{Au}-\mathrm{P} \sim 2 \times 90^{\circ}\right.$ and $\left.180^{\circ}\right)$ in the lowest triplet excited state. Omary and co-workers ${ }^{23}$ showed this conclusion could be extended to neutral, threecoordinate $\mathrm{Au}^{\mathrm{I}}$ complexes of the type $\mathrm{Au}$ (phosphine) ${ }_{2} \mathrm{X}(\mathrm{X}=$ univalent anion, e.g., chloride, bromide or iodide). The results of these theoretical predictions have been utilized by the experimental group of Omary to design series of novel luminescent materials with tunable emission colors, including a highly coveted blue phosphor with brightness and lifetimes that are suitable for molecular light-emitting diodes. ${ }^{23}$ As part of this research on the triplet excited states of $\mathrm{Au}^{\mathrm{I}} \mathrm{L}_{3}$ complexes, it was hypothesized that the promotion of an electron from the $5 \mathrm{~d}$ to the $6 \mathrm{p}$ manifold, which provides the driving force for the photoinduced Jahn-Teller distortion, was akin to a one-electron oxidation of the $d$ orbital manifold of the $d^{10} \operatorname{gold}(\mathrm{I})$ ion (i.e., $\left.{ }^{1} \mathrm{Au} \mathrm{u}^{\mathrm{I}}-5 \mathrm{~d}^{10} 6 \mathrm{p}^{0} \rightarrow{ }^{3} \mathrm{Au} \mathrm{u}^{\mathrm{I}}-5 \mathrm{~d}^{9} 6 \mathrm{p}^{1}\right) .{ }^{22}$ Our earlier work further suggested that $\mathrm{d}^{9}-\mathrm{Au}^{\mathrm{II}} \mathrm{L}_{3}$ complexes would possess a $\mathrm{T}$-shape in the doublet ground states, a supposition supported by density functional calculations on the parent model $\left(\left[\mathrm{Au}\left(\mathrm{PH}_{3}\right)_{3}\right]^{2+}\right)$ and hybrid quantum mechanical/molecular mechanical calculations on larger phosphine complex models $\left(\left[\mathrm{Au}^{\mathrm{II}}\left(\mathrm{PR}_{3}\right)_{3}\right]^{2+}, \mathrm{PR}_{3}=\right.$ $\mathrm{TPA}, \mathrm{PMe}_{3}, \mathrm{PPh}_{3}, \mathrm{PCy}_{2} \mathrm{Ph}, \mathrm{Cy}=$ cyclohexyl, TPA $=1,3,5-$ triaza-7-phospha-adamantane. ${ }^{22}$ Hence, $\mathrm{Au}^{\mathrm{II}}$ complexes can be seen as ground-state models of excited-state $\mathrm{Au}^{\mathrm{I}}$ complexes, and thus may possess interesting spectroscopic, magnetic, and other physicochemical properties.

Recent research on the formation of gold nanoparticles has given added impetus to the study of gold disproportionation and hence $\mathrm{Au}^{\mathrm{II}}$ chemistry. ${ }^{19}$ El-Sayed et al. have recently reported the use of gold nanoparticles for biomedical imaging, whereupon these materials display a variety of photochemical, photophysical, and cytotoxic advantages versus competing technologies. ${ }^{24}$ Caruso et al. have discussed $\mathrm{Au}^{\mathrm{II}}$ disproportionation to $\mathrm{Au}^{\mathrm{I}}$ and $\mathrm{Au}^{\mathrm{III}}$ in the formation of colloidal gold under sonochemical conditions. ${ }^{25}$

For the above reasons, we have undertaken density functional theory studies of $\mathrm{Au}^{\mathrm{II}}$ complexes, in particular disproportionation (also known as dismutation) reactions to $\mathrm{Au}^{\mathrm{I}}$ and $\mathrm{Au}^{\mathrm{III}}$ species, and to assess the stability and extent of paramagnetism in $\mathrm{Au}^{\mathrm{II}}$ complexes. Ligands studied include water, ammonia, carbon monoxide, acetonitrile, methyl isonitrile, phosphines, pyridine, and chloride. For the gold-chloride complexes, we probe the mechanism (dissociative versus associative) and the transition states for the disproportionation of $\mathrm{Au}^{\mathrm{II}}$ to $\mathrm{Au}^{\mathrm{I}}$ and $\mathrm{Au}^{\mathrm{III}}$ complexes.

\section{Computational Methods}

The Gaussian 98 program $^{26}$ was used for the calculations described herein. The B3PW91 hybrid functional ${ }^{27}$ was employed along with the LANL pseudopotentials and their attendant valence basis sets. ${ }^{28}$ The basis set of gold was augmented by two f functions (as per Pyykkö) ${ }^{29}$ and one CoutyHall outer $\mathrm{p}$ function ${ }^{30}$ (contracted). Main group basis sets were augmented with a d polarization function taken from the $6-31 \mathrm{G}^{*}$ basis set. We term this basis set combination LANL2DZ(2f,p)*. For modeling solvent effects, we employed the CPCM (conductor polarizable continuum method) technique ${ }^{31}$ for solvents of moderate (acetonitrile, $\epsilon=36.64$ ) and high (water, $\epsilon=78.39$ ) dielectric constants. All $\mathrm{Au}^{\mathrm{I}} \mathrm{L}_{2}$ and $\mathrm{Au}^{\mathrm{III}} \mathrm{L}_{4}$ complexes are singlets and were studied using restricted Kohn-Sham methods. The $\mathrm{d}^{9}-\mathrm{Au}^{\mathrm{II}} \mathrm{L}_{x}$ complexes are open-shell entities (doublets), and their calculation employed unrestricted Kohn-Sham methods; spin contamination as measured by the $\left\langle\mathrm{S}^{2}\right\rangle$ expectation value was minimal.

Isolation of the disproportionation transition state used the QST3 method. ${ }^{32}$ Other stationary points (all minima, i.e., zero imaginary frequencies as confirmed by calculation of the energy Hessian at the calculated stationary point) are obtained by gradient-driven geometry optimization using analytical gradients. Quoted free energies are obtained through the use of DFTderived vibrational frequencies (unscaled) and are calculated at STP.

\section{Results and Discussion}

1. Disproportionation of Atomic Ions. a. Gas-Phase Ionization Potentials. Before embarking on the study of molecular species, atomic species were investigated because experimental data are rare for $\mathrm{Au}^{\mathrm{II}}$ in a molecular environment. Korgaonkar and co-workers ${ }^{33}$ reported the higher ionization potentials of gold in 1981. These workers deduced values (in $\mathrm{kcal} / \mathrm{mol})$ of $213\left(\mathrm{IP}_{1}\right), 473\left(\mathrm{IP}_{2}\right)$, and $784\left(\mathrm{IP}_{3}\right)$. Extremely highlevel calculations (large basis sets, coupled cluster single, and double excitation wave function built upon a Dirac-CoulombBreit Hamiltonian) have been reported by Eliav et al. and provide insight into the effort that needs to be expended for quantitative calculations of atomic IPs. ${ }^{34}$

Two sets of calculations were carried out on the series ${ }^{2} \mathrm{Au}^{0}$, ${ }^{1} \mathrm{Au}^{+},{ }^{2} \mathrm{Au}^{2+},{ }^{3} \mathrm{Au}^{3+}$ (leading superscript refers to the groundstate multiplicity) to calculate $\mathrm{IP}_{1,2,3}$ using the DFT approach employed in our previous research on gold chemistry ${ }^{22}$ (B3PW91/ $\left.\operatorname{LANLDZ}(2 \mathrm{f}, \mathrm{p})^{*}\right)$. The more expensive post-Hartree-Fock method $(\operatorname{CCSD}(\mathrm{T}))^{35}$ is utilized in the present research to study atoms and atomic ions. The calculated ionization potentials are in good agreement with experiment $(\mathrm{kcal} / \mathrm{mol}): \quad \mathrm{IP}_{1}=215$ (DFT), $205(\mathrm{CCSD}(\mathrm{T}))$; $\mathrm{IP}_{2}=481$ (DFT), $462(\mathrm{CCSD}(\mathrm{T}))$; $\mathrm{IP}_{3}=764$ (DFT), $759(\mathrm{CCSD}(\mathrm{T}))$.

For atomic species, the difference between the second (eq 1) and third (eq 2) ionization potentials is the disproportionation of two $\mathrm{Au}^{2+}$ ions to $\mathrm{Au}^{+}$and $\mathrm{Au}^{3+}$ (eq 3). As gas-phase ionization potentials increase with increasing charge on the atomic species, the quantity " $\mathrm{IP}_{3}-\mathrm{IP}_{2}$ " will necessarily be positive. Utilizing experimental ionization potentials ${ }^{33}$ yields a disproportionation energy of $311 \mathrm{kcal} / \mathrm{mol}$ for atomic ions. The disproportionation energy computed at the B3PW91/ LANL2DZ(2f,p)* level of theory is $283 \mathrm{kcal} / \mathrm{mol}$, with the $\operatorname{CCSD}(\mathrm{T})$ value being $296 \mathrm{kcal} / \mathrm{mol}$, both in reasonable agreement with experiment. ${ }^{33}$

$$
\begin{gathered}
\mathrm{Au}^{2+}+\mathrm{e}^{-} \rightarrow \mathrm{Au}^{+}-\mathrm{IP}_{2} \\
\mathrm{Au}^{2+} \rightarrow \mathrm{Au}^{3+}+\mathrm{e}^{-}+\mathrm{IP}_{3} \\
2 \mathrm{Au}^{2+} \rightarrow \mathrm{Au}^{+}+\mathrm{Au}^{3+} \mathrm{IP}_{3}-\mathrm{IP}_{2}
\end{gathered}
$$

b. Solvent Effects. Solvent effects are expected to play a significant role in a process such as disproportionation given the presence of ionic complexes and the importance of electrostatics in describing the metal-ligand bonds. Utilizing 
TABLE 1: Relativistic Effects and Gold Ionization Potentials $^{a}$

\begin{tabular}{ccccc}
\hline property & $\mathrm{IP}(\mathrm{NR})_{\mathrm{DFT}}$ & $\mathrm{IP}(\mathrm{R})_{\mathrm{DFT}}$ & $\mathrm{IP}(\mathrm{NR})_{\mathrm{CC}}$ & $\mathrm{IP}(\mathrm{R})_{\mathrm{CC}}$ \\
\hline $\mathrm{IP}_{1}$ & 154.1 & 196.0 & 156.8 & 210.6 \\
$\mathrm{IP}_{2}$ & 542.7 & 520.7 & 505.1 & 496.0 \\
$\mathrm{IP}_{3}$ & 876.6 & 846.9 & 817.0 & 807.2
\end{tabular}

${ }^{a}$ Ionization potentials $(\mathrm{kcal} / \mathrm{mol})$ calculated as differences in electronic energies of appropriate atomic and atomic ion states. NR and $\mathrm{R}$ denote nonrelativistic and relativistic pseudopotentials, respectively $;{ }^{38}$ DFT and CC denote B3PW91 and CCSD(T) methods, respectively.

the PCM methodology (a simplistic solvation model for atomic metal ions) ${ }^{36}$ to simulate an aqueous reaction field, it is calculated that solvation substantially alters the energetics of the disproportionation reaction. The gas-phase energy of eq 3 calculated by B3PW91/LANL2DZ(2f,p)* is more than halved, going from $283 \mathrm{kcal} / \mathrm{mol}$ in the gas phase to $119 \mathrm{kcal} / \mathrm{mol}$ in aqueous environment $\left(\mathrm{PCM}-\mathrm{H}_{2} \mathrm{O}\right)$. While the dearth of reliable redox data for $\mathrm{Au}^{2+}$ species plus the crudity of our solvation model conspire to forestall quantitative comparisons, the calculations lead to the reasonable supposition that the greater favorability of $\mathrm{Au}^{2+}$ disproportionation in water is driven by the large solvation energy of the $3+$ gold ion: PCM calculated $\Delta G_{\text {solv }}$ in water $(\mathrm{kcal} / \mathrm{mol})=-4\left({ }^{2} \mathrm{Au}^{0}\right),-79\left({ }^{1} \mathrm{Au}^{+}\right),-326$ $\left({ }^{2} \mathrm{Au}^{2+}\right)$, and $-736\left({ }^{3} \mathrm{Au}^{3+}\right)$. In terms of synthesizing stable, bona fide $\mathrm{Au}^{2+}$ monometallic complexes, these results imply that solvent choice will play an important role in synthetic efforts.

c. Effect of Relativity on Disproportionation. Relativistic effects are known to play a substantial role in the chemistry of gold. ${ }^{37}$ Schwerdtfeger and co-workers have compared IPs calculated with nonrelativistic Hartree-Fock calculations and relativistic Dirac-Fock calculations. ${ }^{10}$ Hence, we sought to estimate the magnitude of relativistic effects upon the disproportionation of gold(II). To this end, we utilized the relativistic (R) and nonrelativistic (NR) pseudopotentials and basis sets of Hay, Wadt, Kahn, and Bobrowicz (HWKB). ${ }^{38}$ Both schemes were employed in conjunction with $\operatorname{DFT}^{39}$ and $\operatorname{CCSD}(\mathrm{T})^{35}$ methods. These results are organized in Table 1.

The largest effect of relativity is on the first ionization potential of gold, Table 1 . With both DFT and CCSD(T) methods, the inclusion of relativistic effects increases $\mathrm{IP}_{1}$ by $\sim 50 \mathrm{kcal} / \mathrm{mol}$. Interestingly, the relativistic effects on $\mathrm{IP}_{2}$ and $\mathrm{IP}_{3}$, which are more pertinent to disproportionation reactions, are much smaller than these effects on $\mathrm{IP}_{1}$. For both the B3PW91 and $\operatorname{CCSD}(\mathrm{T})$ methods, relativity decreases $\mathrm{IP}_{2}(22 \mathrm{kcal} / \mathrm{mol}$ for the former; $9 \mathrm{kcal} / \mathrm{mol}$ for the latter) and also $\mathrm{IP}_{3}(30 \mathrm{kcal} /$ mol for DFT, $10 \mathrm{kcal} / \mathrm{mol}$ for $\operatorname{CCSD}(\mathrm{T})$ ). The same relative changes, although different in magnitude, of gold IPs with respect to inclusion of relativistic effects have been observed by Schwerdtfeger et al. ${ }^{10}$ As the NR-HWKB calculations overestimate both $\mathrm{IP}_{2}$ and $\mathrm{IP}_{3}$ by roughly the same magnitude (Table 1), the resultant difference (i.e., the gas-phase disproportionation energy, $\left.\Delta E_{\text {disp }}\right)$ is remarkably unaffected by relativistic effects: $\Delta E_{\text {disp }}(\mathrm{kcal} / \mathrm{mol})=334(\mathrm{~B} 3 \mathrm{PW} 91 / \mathrm{NR}-$ HWKB) versus 326 (B3PW91/R-HWKB); 312 (CCSD(T)/ NR-HWKB) versus $311(\mathrm{CCSD}(\mathrm{T}) / \mathrm{R}-\mathrm{HWKB})$.

2. Disproportionation of $\mathrm{Au}^{\mathrm{II}}$ Chloride Complexes. Possible pathways for disproportionation of gold-chloride complexes have been evaluated. Recently, El-Sayed et al. ${ }^{19}$ have utilized gold chlorides for the deposition of gold nanoparticles via a mechanism for which they implicate $\mathrm{Au}^{\mathrm{II}}$ disproportionation. Likewise, work by Caruso and co-workers discussed the mechanism of colloidal gold formation in terms of disproportionation of divalent gold complexes. ${ }^{25}$ In the current research, both dissociative and associative mechanisms have been ex-
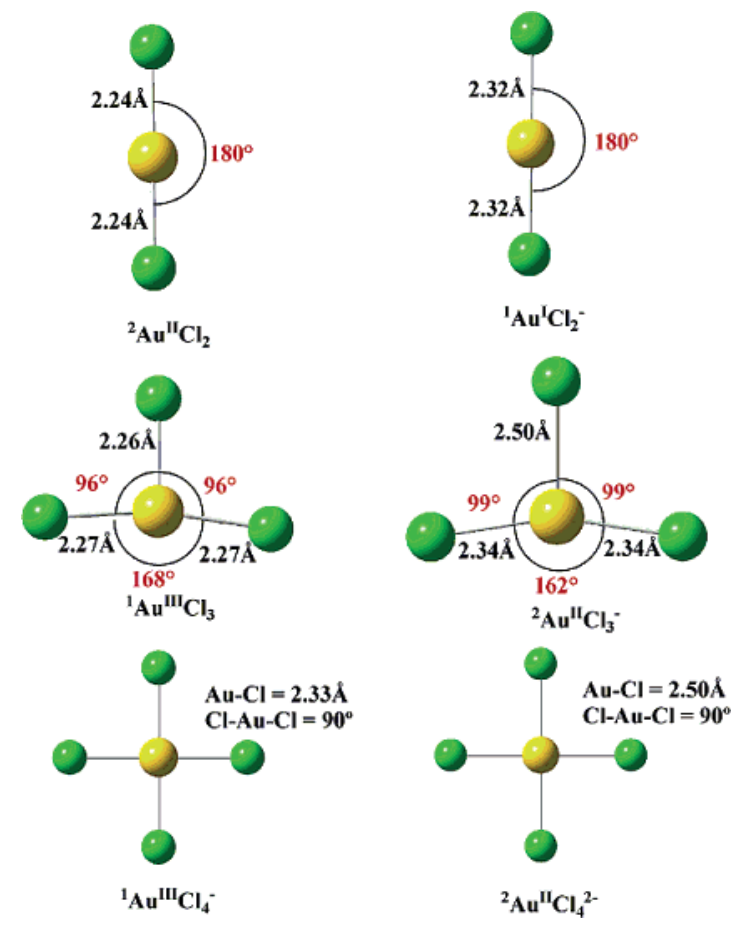

Figure 1. B3PW91/LANL2DZ $(2 \mathrm{f}, \mathrm{p})^{+*}$ calculated metric data for gold-chloride complexes. Superscript prefix denoted multiplicity.

plored. The overall disproportionation reaction studied is given in eq 4.

$$
2^{2} \mathrm{AuCl}_{3}^{-} \rightarrow{ }^{1} \mathrm{AuCl}_{2}{ }^{-}+{ }^{1} \mathrm{AuCl}_{4}^{-}
$$

Schröder et al. ${ }^{8}$ conclude that the neutral disproportionation $\left(2 \mathrm{AuCl}_{2} \rightarrow \mathrm{AuCl}+\mathrm{AuCl}_{3}\right)$ is endothermic by $+38 \mathrm{kcal} / \mathrm{mol}$ for the neutral reaction. We obtain a free energy change of +24 $\mathrm{kcal} / \mathrm{mol}$ for this process with B3PW91/LANL2DZ(2f,p) ${ }^{+*}$ calculations.

a. Dissociative Mechanisms. Calculated metric data for goldchloride complexes are given in Figure 1. The overall disproportionation of two $\mathrm{AuCl}_{3}{ }^{-}$to $\mathrm{AuCl}_{2}{ }^{-}$and $\mathrm{AuCl}_{4}{ }^{-}$, eq 4, is exergonic by $21 \mathrm{kcal} / \mathrm{mol}$ in the gas-phase at the B3PW91/ LANL2DZ $(2 \mathrm{f}, \mathrm{p})^{+*}$ level of theory; the "+" sign indicates the addition of a diffuse set of $\mathrm{s}$ and $\mathrm{p}$ functions taken from the $6-31+\mathrm{G}^{*}$ basis set for chlorine to our standard methodology; this basis set augmentation was deemed prudent given the anionic nature of the complexes. The favorability of eq 4 is consistent with predictions based on electrostatics given the formation of four very polar $\mathrm{Au}^{3+}{ }_{-} \mathrm{Cl}^{-}$bonds for the $\mathrm{Au}$ (III) product.

The incorporation of aqueous solvent effects using the CPCM $\operatorname{method}^{31}(\epsilon=78.39)$ has minimal effect on the thermodynamics of gold-chloride disproportionation as the overall reaction involves two monoanionic species on both the reactant and product side, and whose individual free energies of aquation thus largely cancel out. Although the overall disproportionation of the gold chlorides is little effected by solvation, there is a marked impact due to aquation on individual steps of the disproportionation. Chloride loss from $\mathrm{AuCl}_{3}{ }^{-}$is highly endergonic in the gas phase $\left(\Delta G_{\text {gas }}=+46 \mathrm{kcal} / \mathrm{mol}\right)$ but becomes more feasible in aqueous phase $\left(\Delta G_{\mathrm{aq}}=+15 \mathrm{kcal} / \mathrm{mol}\right)$, Table 2 , largely driven by the high free energy of solvation of the chloride ion $\left(\Delta G_{\text {solv }}=-79 \mathrm{kcal} / \mathrm{mol}\right)$ that is produced.

After initial chloride loss from $\mathrm{AuCl}_{3}{ }^{-}$reactants, we investigated alternative pathways to obtain $\mathrm{AuCl}_{2}{ }^{-}$and $\mathrm{AuCl}_{4}{ }^{-}$ products: (a) electron transfer followed by chloride transfer and 
TABLE 2: Dissociative Mechanisms for Disproportionation ${ }^{a}$

\begin{tabular}{|c|c|c|c|}
\hline mechanism $^{b}$ & $\Delta G_{\text {gas }}$ & $\Delta G_{\text {solv }}$ & $\Delta G_{\mathrm{aq}}$ \\
\hline${ }^{2} \mathrm{AuCl}_{3}^{-} \rightarrow{ }^{2} \mathrm{AuCl}_{2}+\mathrm{Cl}^{-}$ & 46.1 & -31.4 & \\
\hline${ }^{2} \mathrm{AuCl}_{3}{ }^{-}+\mathrm{Cl}^{-} \rightarrow{ }^{2} \mathrm{AuCl}_{4}{ }^{2-}$ & 56.3 & -50.9 & \\
\hline${ }^{2} \mathrm{AuCl}_{4}{ }^{2-}+{ }^{2} \mathrm{AuCl}_{2} \rightarrow \mathrm{AuCl}_{4}{ }^{-}+\mathrm{AuCl}_{2}{ }^{-}$ & -123.6 & 80.3 & \\
\hline $2^{2} \mathrm{AuCl}_{3}^{-} \rightarrow \mathrm{AuCl}_{2}^{-}+\mathrm{AuCl}_{4}^{-}$ & -21.1 & -2.0 & -23 \\
\hline${ }^{2} \mathrm{AuCl}_{3}^{-} \rightarrow{ }^{2} \mathrm{AuCl}_{2}+\mathrm{Cl}^{-}$ & 46.1 & -31.4 & 14 \\
\hline${ }^{2} \mathrm{AuCl}_{3}{ }^{-}+{ }^{2} \mathrm{AuCl}_{2} \rightarrow \mathrm{AuCl}_{2}{ }^{-}+\mathrm{AuCl}_{3}$ & 4.3 & -8.0 & - \\
\hline$+\mathrm{Cl}-\rightarrow \mathrm{AuCl}_{4}^{-}$ & -71.5 & 37.4 & -34 \\
\hline$+\mathrm{AuCl}_{4}^{-}$ & -21.1 & -2.0 & -23 \\
\hline$\rightarrow \mathrm{AuCl}_{2-}+{ }^{2} \mathrm{Cl}^{\bullet}$ & 23.1 & -3.3 & \\
\hline${ }^{2} \mathrm{AuCl}_{3}{ }^{-}+{ }^{2} \mathrm{Cl}^{\cdot} \rightarrow \mathrm{AuCl}_{4}^{-}$ & -44.2 & 1.3 & -42 \\
\hline $2 \mathrm{AuCl}_{3}^{-} \rightarrow \mathrm{AuCl}_{2}^{-}+\mathrm{AuCl}_{4}^{-}$ & -21.1 & -2.0 & -23 \\
\hline
\end{tabular}

${ }^{a} \Delta G_{\mathrm{gas}}(\mathrm{kcal} / \mathrm{mol})$ is the free energy of the reaction in the gas-phase; $\Delta G_{\text {solv }}(\mathrm{kcal} / \mathrm{mol})$ is the solvent contribution (calculated at the gasphase optimized geometries using the PCM-water methodology) for the reaction of interest; $\Delta G_{\text {aq }}=\Delta G_{\text {gas }}+\Delta G_{\text {solv }}$. Calculated at the B3PW91/LANL2DZ(2f,p) ${ }^{+*}$ level of theory. ${ }^{b}$ The prefix ${ }^{2}$ indicates the doublet multiplicity of the particular species; other species are singlets.

(b) a mechanism in which this sequence is reversed, i.e., first chloride then electron transfer. Addition of chloride to $\mathrm{AuCl}_{3}{ }^{-}$ is endergonic $\left(\Delta G_{\mathrm{aq}}=+5 \mathrm{kcal} / \mathrm{mol}\right)$ but is followed by a very exergonic electron-transfer step $\left(\Delta G_{\mathrm{aq}}=-43 \mathrm{kcal} / \mathrm{mol}\right)$. For the alternative mechanism, both steps are exergonic in aqueous media: by $-4 \mathrm{kcal} / \mathrm{mol}$ for the initial electron transfer and by $-34 \mathrm{kcal} / \mathrm{mol}$ for the subsequent chloride addition to produce $\mathrm{AuCl}_{4}{ }^{-}$.

Another pathway investigated involved initial electron transfer as a discrete step between $\left[\mathrm{Au}^{\mathrm{II}} \mathrm{Cl}_{3}\right]^{-}$to produce $\left[\mathrm{Au}^{\mathrm{I}} \mathrm{Cl}_{3}\right]^{2-}$ and $\mathrm{AuCl}_{3}$. However, the former $\mathrm{Au}^{\mathrm{I}}$ species could not be isolated through computation as a stable entity. B3PW91/ LANL2DZ $(2 \mathrm{f}, \mathrm{p})^{+*}$ geometry optimization in both the gas-phase and in a high polarity solvent (CPCM, $\epsilon=78.39)$ gave dissociation of a chloride ion, resulting in $\mathrm{Au}^{\mathrm{I}} \mathrm{Cl}_{2}{ }^{-} \cdot \mathrm{Cl}^{-}$.

A mechanism involving chlorine atom transfer is competitive with chloride transfer in the gas phase but is substantially less so in aqueous environment. Chlorine atom loss from $\mathrm{AuCl}_{3}{ }^{-}$is endergonic by $20 \mathrm{kcal} / \mathrm{mol}(\sim 5 \mathrm{kcal} / \mathrm{mol}$ more endergonic than $\mathrm{Cl}^{-}$loss in aqueous media). The $\mathrm{Cl}$ atom loss is counterbalanced by a very favorable free energy for addition of the chlorine atom, being a free radical, to a second equivalent of $\mathrm{AuCl}_{3}{ }^{-}$.

Caruso et al. ${ }^{25}$ propose a slight modification to the disproportionation given in eq 4 , see eq 5 . The

$$
2 \mathrm{AuCl}_{4}{ }^{2-} \rightarrow \mathrm{AuCl}_{2}^{-}+\mathrm{AuCl}_{4}^{-}+2 \mathrm{Cl}^{-}
$$

dissociation of chloride from $\mathrm{AuCl}_{4}{ }^{2-}$ is calculated to be exergonic, both in the gas-phase $(-56 \mathrm{kcal} / \mathrm{mol})$ and in aqueous solution $(-5 \mathrm{kcal} / \mathrm{mol})$. Hence, chloride loss from $\mathrm{AuCl}_{4}{ }^{2-}$ is calculated to be spontaneous. As $\mathrm{AuCl}_{3}{ }^{-}$is the product of this spontaneous chloride loss, $\mathrm{AuCl}_{4}{ }^{2-}$, if formed in solution, will decompose and then lead into the pathways discussed above.

b. Associative Mechanism. A variety of transition state geometries (one or more bridging chlorides, with or without direct $\mathrm{Au}-\mathrm{Au}$ bonding, planar versus nonplanar geometries, etc.) were investigated for associative transfer of chlorine to form $\mathrm{AuCl}_{2}{ }^{-}$and $\mathrm{AuCl}_{4}{ }^{-}$directly from two $\mathrm{AuCl}_{3}{ }^{-}$. All attempts either reduced to the transition state found, or yielded minima already obtained. The transition state isolated possesses the formula $\mathrm{Au}_{2} \mathrm{Cl}_{6}{ }^{2-}$ with the geometry given in Figure 2.

The calculated disproportionation transition state is $60 \mathrm{kcal} /$ mol above separated $\mathrm{AuCl}_{3}{ }^{-}$ions in the gas phase but only +9 $\mathrm{kcal} / \mathrm{mol}$ in aqueous phase. Atomic charges from a natural bond orbital (NBO) analysis ${ }^{40}$ indicate a slightly higher positive

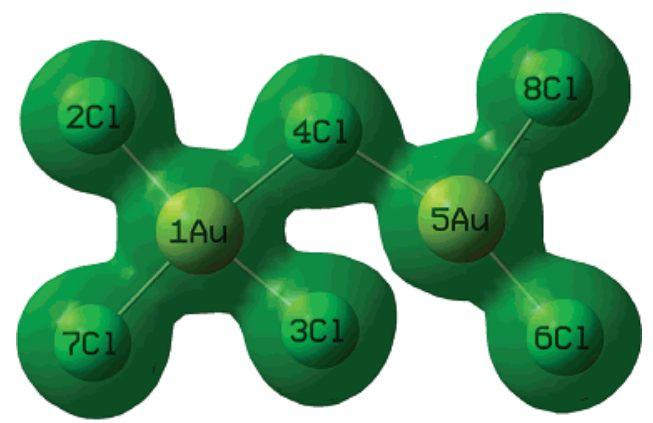

Figure 2. Calculated singlet transition state for the associative disproportionation mechanism. The total electron density is plotted (isovalue $=0.04)$. Bond distances $(\AA)$ : $\mathrm{Cl}(2)-\mathrm{Au}(1)=2.42 ; \mathrm{Cl}(7)-$ $\mathrm{Au}(1)=2.44 ; \mathrm{Au}(1)-\mathrm{Cl}(4)=2.46 ; \mathrm{Au}(1)-\mathrm{Cl}(3)=2.41 ; \mathrm{Cl}(4)-\mathrm{Au}-$ $(5)=2.53 ; \mathrm{Au}(5)-\mathrm{Cl}(8)=2.56 ; \mathrm{Au}(5)-\mathrm{Cl}(6)=2.47 ; \mathrm{Au}(1)-\mathrm{Cl}(3)$ $=2.41 ; \mathrm{Cl}(3)-\mathrm{Au}(5)=3.09 ; \mathrm{Au}(1)-\mathrm{Au}(5)=4.15$. Bond angles $\left({ }^{\circ}\right)$ : $\mathrm{Cl}(2)-\mathrm{Au}(1)-\mathrm{Cl}(3)=173.8 ; \mathrm{Cl}(2)-\mathrm{Au}(1)-\mathrm{Cl}(4)=92.2 ; \mathrm{Cl}(3)-\mathrm{Au}-$ $(1)-\mathrm{Cl}(4)=81.9 ; \mathrm{Au}(1)-\mathrm{Cl}(4)-\mathrm{Au}(5)=112.3 ; \mathrm{Cl}(4)-\mathrm{Au}(5)-\mathrm{Cl}-$ (6) $=158.6 ; \mathrm{Cl}(2)-\mathrm{Au}(1)-\mathrm{Cl}(7)=91.7 ; \mathrm{Cl}(3)-\mathrm{Au}(1)-\mathrm{Cl}(7)=94.0$; $\mathrm{Cl}(4)-\mathrm{Au}(1)-\mathrm{Cl}(7)=174.4 ; \mathrm{Cl}(4)-\mathrm{Au}(5)-\mathrm{Cl}(8)=94.9 ; \mathrm{Cl}(6)-\mathrm{Au}-$ $(5)-\mathrm{Cl}(8)=105.9$.

TABLE 3: Disproportionation Free Energies (kcal/mol) of $\mathrm{Au}^{\mathrm{II}} \mathrm{L}_{3}$ Complexes in Aqueous Media ${ }^{a}$

\begin{tabular}{lccccccc}
\hline \multicolumn{1}{c}{$\mathrm{L}$} & $\Delta G_{\text {rxn,gas }}$ & $\Delta G_{(1, \mathrm{aq})}$ & $\Delta G_{(2, \mathrm{aq})}$ & $\Delta G_{(3, \mathrm{aq})}$ & $\Delta G_{\text {solv }}$ & $\Delta G_{\text {rxn,aq }}$ & $\rho_{\text {spin }}{ }^{b}$ \\
\hline $\mathrm{PH}_{3}$ & 43.8 & -39.8 & -173.2 & -375.7 & -69.0 & -25.2 & 0.35 \\
$\mathrm{CO}$ & 72.6 & -54.3 & -208.8 & -432.5 & -69.2 & +3.4 & 0.50 \\
$\mathrm{MeCN}$ & 41.4 & -36.5 & -148.7 & -314.1 & -53.2 & -11.8 & 0.64 \\
$\mathrm{MeNC}$ & 21.5 & -39.4 & -154.3 & -322.4 & -53.2 & -31.7 & 0.50 \\
$\mathrm{NH}_{3}$ & 59.2 & -56.3 & -207.4 & -444.8 & -86.3 & -27.1 & 0.52 \\
$\mathrm{OH}_{2}$ & 88.0 & -53.0 & -242.6 & -514.6 & -92.4 & -4.3 & 0.63 \\
$\mathrm{Py}$ & 23.7 & -45.1 & -150.1 & -282.1 & -27.0 & -3.3 & 0.48
\end{tabular}

${ }^{a} \Delta G_{\mathrm{rxn}, \mathrm{gas}}$ is the energy of the disproportionation reaction (eq 6) in the gas phase; $\Delta G_{(1, \text { aq })}$ is the calculated free energy of aquation of ${ }^{1}\left[\mathrm{Au}^{\mathrm{I}} \mathrm{L}_{2}\right] ; \Delta G_{(2, \text { aq })}$ is the calculated free energy of aquation of ${ }^{2}\left[\mathrm{Au}^{\mathrm{II}} \mathrm{L}_{3}\right]$; $\Delta G_{(3, \text { aq })}$ is the calculated free energy of aquation of ${ }^{1}\left[\mathrm{Au}^{\mathrm{III}} \mathrm{L}_{4}\right]$; $\Delta G_{\text {solv }}=\Delta G_{(3, \mathrm{aq})}+\Delta G_{(1, \mathrm{aq})}-2 \Delta G_{(1, \mathrm{aq})} ; \Delta G_{\text {rxn,aq }}=\Delta G_{\text {rxn,gas }}+\Delta G_{\text {solv }}$. $\mathrm{Py}=$ pyridine. ${ }^{b}$ Spin density (in $\mathrm{e}^{-}$) on the $\mathrm{Au}$ atom in ${ }^{2} \mathrm{Au}^{\mathrm{II}} \mathrm{L}_{3}$ (gasphase). CPCM spin densities are nearly identical to gas-phase spin densities.

charge of +0.9 on $\mathrm{Au}(1)$ versus +0.8 on $\mathrm{Au}(5)$; see Figure 2 for the atom numbering scheme. The NBO analysis is complicated by the delocalization in both the $\sigma$ and $\pi$ frameworks of $\left[\mathrm{Au}_{2} \mathrm{Cl}_{6}\right]^{2-}$. A plot of the total density (which is superimposed upon the calculated transition state geometry in Figure 2) implies no $\mathrm{Au} \cdots \mathrm{Au}$ interaction and weak interaction between $\mathrm{Cl}(3)$ and $\mathrm{Au}(5){ }^{41}$

For the dissociative mechanisms evaluated in the previous section, the loss of chlorine, either as an atom $(20 \mathrm{kcal} / \mathrm{mol}$, Table 2) or as an anion (15 kcal/mol, Table 2), represents the largest intrinsic barrier calculated in aqueous solution. The calculated transition state for associative disproportionation is $9 \mathrm{kcal} / \mathrm{mol}$ above separated $\mathrm{Au}^{\mathrm{II}} \mathrm{Cl}_{3}{ }^{-}$anions, suggesting an associative mechanism for disproportionation of gold chlorides in aqueous media.

3. Disproportionation of $\mathrm{Au}^{\mathrm{II}} \mathbf{L}_{3}$ Complexes. In this section, we investigate ligand and solvent effects on our model disproportionation reaction, eq 6 , for neutral ligands $\left(\mathrm{L}=\mathrm{PH}_{3}, \mathrm{CO}\right.$, $\mathrm{NH}_{3}, \mathrm{OH}_{2}$, pyridine, $\mathrm{MeCN}$, or MeNC). Calculated free energies in the gas phase and solution (CPCM water and acetonitrile) are compiled in Table 3, along with calculated solvation free energies for individual complexes.

$$
2^{2}\left[\mathrm{Au}^{\mathrm{II}} \mathrm{L}_{3}\right] \rightarrow{ }^{1}\left[\mathrm{Au}^{\mathrm{I}} \mathrm{L}_{2}\right]+{ }^{1}\left[\mathrm{Au}^{\mathrm{III}} \mathrm{L}_{4}\right]
$$

There are several interesting conclusions that emerge from the data in Table 3. First, the disproportionation reaction is 
highly endergonic in the gas phase, ranging from $+21.5 \mathrm{kcal} /$ mol for the isonitrile complex $\left[\mathrm{Au}(\mathrm{MeNC})_{3}\right]^{2+}$ to $+88.0 \mathrm{kcal} /$ mol for disproportionation of the aqua complex $\left[\mathrm{Au}\left(\mathrm{H}_{2} \mathrm{O}\right)_{3}\right]^{2+}$. No obvious trends with electron donating/accepting behavior of the ligands are obvious and indeed may not be expected as disproportionation involves a subtle balance of factors due to the requirement for electron and ligand transfer. The latter is expected to be favored for weakly ligated ligands. The former is more complicated as ligands that make the $\mathrm{Au}^{\mathrm{I}}$ complex a better electron donor may also make the $\mathrm{Au}^{\mathrm{III}}$ complex a worse electron acceptor. Comparison of the data in Table 3 with the earlier results given for atomic ion species does indicate that the ligands do ameliorate the endergonicity of the gas-phase disproportionation reaction.

As computed in a previous study ${ }^{22}$ of tris(phosphine)gold(I) complexes, $\left[\mathrm{Au}^{\mathrm{II}} \mathrm{L}_{3}\right]$ complexes have a $\mathrm{T}$-shape coordination geometry. Analysis of the spin densities highlights the difficulties in assigning oxidation states to formally divalent gold complexes. ${ }^{3-5}$ In the crystal field limit, one expects a single unpaired electron on a $\mathrm{d}^{9}-\mathrm{Au}^{\mathrm{II}}$ ion. However, spin density values from a Mulliken population analysis are substantially less than one electron, ranging from $0.35 \mathrm{e}^{-}$for the complex with $\mathrm{L}=$ $\mathrm{PH}_{3}$ to $0.64 \mathrm{e}^{-}$with $\mathrm{L}=\mathrm{MeCN}$, Table 3. Analyses of EPR spectra of magnetically dilute $\mathrm{Au}(\mathrm{II})$ complexes have indicated delocalization of the unpaired electron onto the ligands; in some cases, this delocalization is very substantial.,11,15,16 Schlupp and Maki propose that only $15 \%$ of the spin density resides on the gold in their bis(maleonitriledithiolato)-gold(II) complex; ${ }^{11}$ we have obtained a very similar value computationally for this complex. ${ }^{42}$ Although the partitioning of total electron density is always arbitrary to some extent, the results emphasize the inherent instability of the $\mathrm{Au}^{\mathrm{II}}$ oxidation state. The low value of $\rho_{\text {spin }}$ for $\mathrm{PH}_{3}$ and comparison of the gold spin density of the MeCN complex $\left(\rho_{\text {spin }}=0.64 \mathrm{e}^{-}\right)$with the isomeric MeNC complex $\left(\rho_{\text {spin }}=0.50 \mathrm{e}^{-}\right)$makes it tempting to interpret the results in terms of the ability of $\sigma$-donor/ $\pi$-acceptor ligands to stabilize $\mathrm{Au}^{\mathrm{II}}$ complexes. ${ }^{20,21}$ However, the computed results are not always so straightforward. For example, $\mathrm{CO}$ is a $\sigma$-donor/ $\pi$-acceptor ligand; yet, its $\mathrm{Au}^{\mathrm{II}}$ complex has a spin density on $\mathrm{Au}$ that is essentially the same as the $\mathrm{Au}^{\mathrm{II}}$ complex with ammonia (only a $\sigma$-donor), i.e., $\rho_{\text {spin }} \sim 0.5 \mathrm{e}^{-}$in both.

Linear correlations with prototypical frontier orbital properties and the calculated spin density on gold $\left(\rho_{\text {spin }}\right)$ were investigated. There is very poor linear correlation with either the KS-HOMO (Kohn-Sham highest occupied molecular orbital) or KSHOMO (Kohn-Sham lowest unoccupied molecular orbital) energy and $\rho_{\text {spin }}{ }^{43}$ Correlation is slightly better between $\rho_{\text {spin }}$ and the $\mathrm{KS}-\mathrm{HOMO} / \mathrm{KS}-\mathrm{LUMO}$ gap although pyridine is an obvious outlier for reasons that are not immediately apparent, Figure 3. We also found no correlation between the free energies of the disproportionation reaction with neither the IP nor the KS-HOMO/KS-LUMO gap of the different L ligands. All of these data suggest no apparent relationship between the stability of the $\mathrm{Au}^{\mathrm{II}} \mathrm{L}_{3}$ complex and the electronic factor of the ligand alone.

The data in Table 3 indicate that the aqueous disproportionation reaction is considerably more favorable than the corresponding gas-phase reaction. Disproportionation is now endergonic for the carbonyl complex, Figure 4. The remaining ligands have exergonic disproportionation reactions in aqueous media. The driving force for this shift in thermodynamics of disproportionation is the very large negative values for the free energies of aquation of the ${ }^{1}\left[\mathrm{Au}^{\mathrm{III}} \mathrm{L}_{4}\right]$ complexes. The solvation free energy contribution to the reaction $\left(\Delta G_{\text {solv }}\right)$ is very large

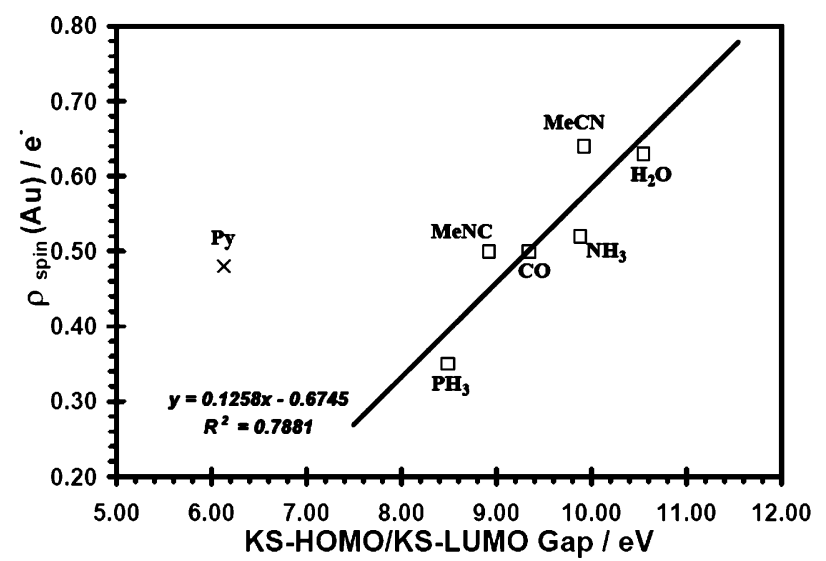

Figure 3. Correlation between the calculated spin density on $\mathrm{Au}$ in $\mathrm{Au}^{\mathrm{II}} \mathrm{L}_{3}{ }^{2+}$ complexes and the calculated $\mathrm{KS}-\mathrm{HOMO} / \mathrm{KS}-\mathrm{LUMO}$ gap. The data point with $\mathrm{L}=\mathrm{Py}$ is not included in the correlation.

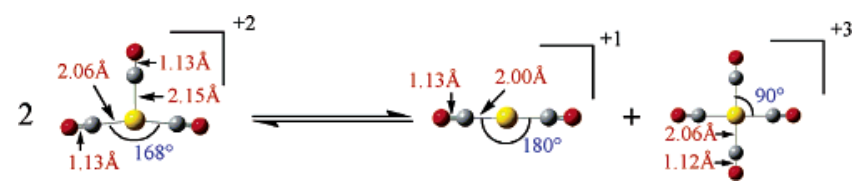

Figure 4. Disproportionation reaction for $\mathrm{L}=\mathrm{CO}$. Bond lengths in $\AA$; bond angles in ${ }^{\circ}$. Reaction is calculated to be endergonic both in aqueous $\left(\Delta G_{\mathrm{rxn}, \mathrm{aq}}=+3.4 \mathrm{kcal} / \mathrm{mol}\right)$ and acetonitrile $\left(\Delta G_{\mathrm{rxn}, \mathrm{aq}}=+5.1\right.$ $\mathrm{kcal} / \mathrm{mol})$ solution.

TABLE 4: Disproportionation Free Energies (kcal/mol) of $\mathrm{Au}^{\mathrm{II}} \mathrm{L}_{3}$ Complexes in Acetonitrile Solution ${ }^{a}$

\begin{tabular}{lcccccc}
\hline ligand & $\Delta G_{\text {rxn,gas }}$ & $\Delta G_{(1, \text { an })}$ & $\Delta G_{(2, \text { an })}$ & $\Delta G_{(3, \text { an })}$ & $\Delta G_{\text {an }}$ & $\Delta G_{\text {rxn,an }}$ \\
\hline $\mathrm{PH}_{3}$ & 43.8 & -33.3 & -151.1 & -330.8 & -61.9 & -18.1 \\
$\mathrm{CO}$ & 72.6 & -44.5 & -179.6 & -382.3 & -67.5 & +5.1 \\
$\mathrm{MeCN}$ & 41.4 & -29.7 & -128.8 & -280.5 & -52.5 & -11.1 \\
$\mathrm{MeNC}$ & 21.5 & -32.3 & -133.0 & -289.1 & -55.4 & -34.0 \\
$\mathrm{NH}_{3}$ & 59.2 & -46.4 & -180.3 & -392.6 & -78.4 & -19.2 \\
$\mathrm{OH}_{2}$ & 88.0 & -51.1 & -202.9 & -443.5 & -88.8 & -0.8 \\
$\mathrm{Py}$ & 23.7 & -32.0 & -124.9 & -262.5 & -44.5 & -20.8
\end{tabular}

${ }^{a} \Delta G_{\mathrm{rxn}, \mathrm{gas}}$ is the energy of the disproportionation reaction (eq 6) in the gas phase; $\Delta G_{(1, \text { an })}$ is the calculated free energy of solvation in acetonitrile of ${ }^{1}\left[\mathrm{Au}^{\mathrm{I}} \mathrm{L}_{2}\right] ; \Delta G_{(2, \text { an })}$ is the calculated free energy of solvation in acetonitrile of ${ }^{2}\left[\mathrm{Au}^{\mathrm{II}} \mathrm{L}_{3}\right] ; \Delta G_{(3, \text { an })}$ is the calculated free energy of solvation in acetonitrile of ${ }^{1}\left[\mathrm{Au}^{\mathrm{I}} \mathrm{L}_{3}\right] ; \Delta G_{\text {an }}=\Delta G_{(3, \text { an })}+\Delta G_{(1, \text { an })}-2$ $\Delta G_{(1, \mathrm{an})} ; \Delta G_{\mathrm{rxn}, \mathrm{an}}=\Delta G_{\mathrm{rxn}, \mathrm{gas}}+\Delta G_{\mathrm{an}}$.

for small, polar ligands such as ammonia and water. For the pyridine complex, the $\Delta G_{\text {solv }}$ is the least negative $(-27.0 \mathrm{kcal} /$ mol), a result consistent with the large size of the ligand (aquation energy is expected to vary inversely with the volume of the solute) and the low-polarity of the $\mathrm{CH}$ groups that are presented to the solvent. As a result, $\Delta G_{\mathrm{rxn}, \mathrm{aq}}$ for the disproportionation of $\left[\mathrm{Au}(\mathrm{Py})_{3}\right]^{2+}$ is only moderately exergonic, -3.3 $\mathrm{kcal} / \mathrm{mol}$. For the aqua complex, the aqueous-phase disproportionation is also mildly exergonic, although, unlike the pyridine complex, this reflects a very unfavorable gas-phase disproportionation counteracted by a very negative solvation free energy, Table 3.

The present results suggest that synthetic efforts toward a monometallic $\mathrm{Au}^{\mathrm{II}}$ complex should utilize as nonpolar a solvent as is feasible, to forestall decomposition to univalent and trivalent gold complexes via disproportionation. This contention is further supported by the data in Table 4 regarding the calculated disproportionation energies and solvation free energies in acetonitrile $(\epsilon=36.64)$. However, the CPCM calculations indicate several exceptions to this generalization due to the variations that exist in the solvation free energies of the various cationic complexes. Disproportionation can be more 
exergonic in acetonitrile than in water: $\Delta G_{\mathrm{rxn}, \mathrm{an}}=-34 \mathrm{kcal} /$ mol vs $\Delta G_{\text {rxn,aq }}=-32 \mathrm{kcal} / \mathrm{mol}$ for $\left[\mathrm{Au}(\mathrm{MeNC})_{3}\right]^{2+}$; $\Delta G_{\mathrm{rxn}, \mathrm{an}}=-21 \mathrm{kcal} / \mathrm{mol}$ vs $\Delta G_{\mathrm{rxn}, \mathrm{aq}}=-3 \mathrm{kcal} / \mathrm{mol}$ for $\left[\mathrm{Au}(\mathrm{Py})_{3}\right]^{2+}$. However, for the majority of complexes, the switch from water to acetonitrile thermodynamically inhibits the disproportionation by $1-8 \mathrm{kcal} / \mathrm{mol}$.

Tables 3 and 4 indicate that a polar environment provides enhanced driving force for the disproportionation of $\mathrm{Au}^{\mathrm{II}}$ complexes, echoing the conclusions of the atomic calculations reported above. Although the choice of solvent in a synthesis is, of course, dictated by a variety of factors, the present calculations indicate that lower polarity solvents may inhibit disproportionation toward the synthesis of stable $\mathrm{Au}^{\mathrm{II}}$ mononuclear complexes.

\section{Summary and Conclusions}

A computational study of gold(II) disproportionation reactions is presented. The effects of ligand, solvent, and relativity are investigated. Several important conclusions have resulted from this research, the most important of which are summarized here.

(1) Solvation substantially alters the energetics of the disproportionation reaction. The gas-phase energy of disproportionation for atomic ions is more than halved, going from 283 $\mathrm{kcal} / \mathrm{mol}$ in the gas-phase to $119 \mathrm{kcal} / \mathrm{mol}$ in the aqueous environment $\left(\mathrm{PCM}-\mathrm{H}_{2} \mathrm{O}\right)$. The greater favorability of the disproportionation in aqueous media is driven by the large solvation energy of the trivalent gold ion. Thus, solvent choice will play an important role in any synthetic effort directed at $\mathrm{Au}^{\mathrm{II}}$ monometallic complexes.

(2) Relativistic effects on the energetics of the atomic disproportionation reaction are minimal.

(3) For the dissociative mechanisms evaluated, the loss of chlorine, either as an atom $\left(\Delta G_{\mathrm{aq}}=+20 \mathrm{kcal} / \mathrm{mol}\right)$ or as an anion $\left(\Delta G_{\mathrm{aq}}=+15 \mathrm{kcal} / \mathrm{mol}\right)$ represents the largest calculated barrier. The calculated transition state for associative disproportionation is $9 \mathrm{kcal} / \mathrm{mol}$ above separated $\mathrm{Au}^{\mathrm{II}} \mathrm{Cl}_{3}{ }^{-}$anions, suggesting an associative mechanism for disproportionation of gold chlorides in aqueous media.

(4) For the disproportionation of $\mathrm{Au}^{\mathrm{II}} \mathrm{L}_{3}$ complexes with neutral ligands, disproportionation is highly endergonic in the gas phase.

(5) The solvation free energy contribution to the reaction $\left(\Delta G_{\text {solv }}\right)$ is influenced by the ligand characteristics. For small and polar ligands such as ammonia and water, $\Delta G_{\text {solv }}$ is very large. Calculations imply that for a monometallic $\mathrm{Au}^{\mathrm{II}}$ complex to be synthesized, a nonpolar solvent is favored over a polar solvent.

(6) The disproportionation reaction is considerably more favorable in solution than in the gas phase. With the exception of $\left[\mathrm{Au}(\mathrm{CO})_{3}\right]^{2+}$, disproportionation of $\mathrm{Au}^{\mathrm{II}} \mathrm{L}_{3}$ complexes to $\mathrm{Au}$ and $\mathrm{Au}^{\mathrm{III}} \mathrm{L}_{3}$ is exergonic for the variety of ligands investigated. As with the atomic species, the driving force is provided by the very favorable solvation free energy of the trivalent gold complex. The present calculations thus suggest that choosing ligands that would lead to neutral species upon disproportionation (e.g., $2 \mathrm{AuX}_{2} \mathrm{~L} \rightarrow \mathrm{AuXL}+\mathrm{AuX}_{3} \mathrm{~L} ; \mathrm{X}=$ univalent ligand, $\mathrm{L}=$ neutral ligand) may provide an effective route to thwart this decomposition pathway for $\mathrm{Au}^{\mathrm{II}}$ complexes. Likewise, bulkier ligands that yield larger, more weakly solvated complex ions appear to be desirable.

Acknowledgment. The authors acknowledge the U.S. Department of Education for their support of CASCaM. Calculations employed the UNT computational chemistry resource, whose purchase was supported by a CRIF grant from the U.S. National Science Foundation (CHE-0342824). The authors acknowledge the U.S. Department of State's Bureau of Educational and Cultural Affairs and the Council for International Exchange of Scholars (CIES) for a Fulbright Scholarship to H.R. to support his stay at the University of North Texas. T.R.C. acknowledges the Office of Basic Energy Sciences, United States Department of Energy for partial support of this research through Grant No. DEFG02-03ER15387. M.A.O. acknowledges partial support of his contribution by the Robert A. Welch Foundation (Grant B-1542) and the National Science Foundation (CAREER Award CHE-0349313). Helpful discussion with and suggestions from Dr. Paul Bagus (Department of Chemistry and CASCaM, UNT) are gratefully acknowledged.

\section{References and Notes}

(1) Laguna, A.; Laguna, M. Coord. Chem. Rev. 1999, 193-195, 837.

(2) Irwin, M. D.; Abdou, H. E.; Mohamed, A. A.; Fackler, J. P., Jr. Chem. Commun. 2003, 2882.

(3) (a) Dell'Amico, D. B.; Calderazzo, F.; Marchetti, F. J. Chem. Soc., Dalton Trans. 1976, 1829. (b) Dell'Amico, D. B.; Calderazzo, F.; Marchetti, F.; Merlino, S.; Perego, G. J. Chem. Soc. Chem. Commun. 1977, 31. (c) Dell'Amico, D. B.; Calderazzo, F.; Marchetti, F.; Merlino, S. J. Chem. Soc., Dalton Trans. 1982, 2257.

(4) Herring, F. G.; Hwang, G.; Lee, K. C.; Mistry, F.; Phillips, P. S.; Willner, H.; Aubke, F. J. Am. Chem. Soc. 1992, 114, 1271.

(5) McMillan, J. A. Chem. Rev. 1962, 62, 65 and references therein.

(6) Schmidbaur, H.; Dash, K. C. Adv. Inorg. Chem. Radiochem. 1982, $25,39$.

(7) (a) Petrenko, T.; Ray, K.; Wieghardt, K. E.; Neese, F. J. Am. Chem. Soc. 2006, 128, 4422. (b) Ray, K.; Weyhermueller, T.; Neese, F.; Wieghardt, K. Inorg. Chem. 2005, 44, 5345. (c) Kay, K.; Weyhermueller, T.; Goossens, A.; Craje, M. W. J.; Wieghardt, K. Inorg. Chem. 2003, 42, 4082.

(8) Schröder, D.; Brown, R.; Schwerdtfeger, P.; Wang, X. B.; Yang, X.; Wang, L. S.; Schwarz, H. Angew. Chem., Int. Ed. 2003, 42, 311.

(9) Blackmore, I. J.; Bridgeman, A. J.; Harris, N.; Holdaway, M. A.; Rooms, J. F.; Thompson, E. L. Young, N. A. Angew. Chem., Int. Ed. 2005, 44, 6746 .

(10) Schwerdtfeger, P.; Boyd, P. D. W.; Brienne, S.; Burrell, A. K. Inorg. Chem. 1992, 31, 3411 .

(11) Schlupp, R. L.; Maki, A. H. Inorg. Chem. 1974, 13, 44. See ref 40 .

(12) Vänngard, T.; Kerström, S. A. Nature 1959, 184, 183.

(13) Bergendahl, T. J.; Bergendahl, E. M. Inorg. Chem. 1972, 11, 638

(14) Warren, L. F.; Hawthorne, M. F. J. Am. Chem. Soc. 1968, 90, 4823

(15) (a) MacCragh, A,; Koski, W. S. J. Am. Chem. Soc. 1963, 85, 2375.

(b) MacCragh, A.; Koski, W. S. J. Am. Chem. Soc. 1965, 87, 2496.

(16) See also: Waters, J. H.; Gray, H. B. J. Am. Chem. Soc. 1965, 87 3534 and Elder, S. H.; Lucier, G. M.; Hollander, F. J.; Bartlett, N. J. Am Chem. Soc. 1997, 119, 1020.

(17) Johnson, W. M.; Dev, R.; Cady, G. H. Inorg. Chem. 1972, 11, 2260.

(18) Seidel, S.; Seppelt, K. Science 2000, 290, 117.

(19) Eustis, S.; Hsu, H.-Y.; El-Sayed, M. A. J. Phys. Chem. B 2005 109,4811 and references therein

(20) Walker, N.; Wright, R.; Barren, P.; Murrell, J.; Stace. A. J. Am Chem. Soc. 2001, 123, 4223.

(21) Walker, N. R.; Wright, R. R.; Barran, P. E.; Stace, A. J. Organomet 1999, $18,3569$.

(22) Barakat, K. A.; Cundari, T. R.; Omary, M. A.; J. Am. Chem. Soc. 2003, 125, 14228. See also: Barakat, K. A.; Cundari, T. R. Chem. Phys. 2005, 311, 3 for a brief analysis of disproportionation without ligand exchange (i.e., $2^{2}\left[\mathrm{Au}^{\mathrm{II}} \mathrm{L}_{3}\right] \rightarrow{ }^{1}\left[\mathrm{Au}^{\mathrm{I}} \mathrm{L}_{3}\right]+{ }^{1}\left[\mathrm{Au}^{\mathrm{III}} \mathrm{L}_{3}\right]$ ).

(23) Sinha, P.; Wilson, A. K.; Omary, M. A. J. Am. Chem. Soc. 2005, 127,12488

(24) El-Sayed, I. H.; Huang, X.; El-Sayed, M. A. Nano Lett. 2005, 5 , 829.

(25) Caruso, R. A.; Ashokkumar, M.; Grieser, F. Langmuir 2002, 18, 7831. See also: Gachard, E.; Remita, H.; Khatouri, J.; Keita, B.; Nadjo, L.; Belloni, J. New J. Chem. 1998, 22, 1257.

(26) Frisch, M. J.; Pople, J. A.; et al. Gaussian 98, revision A.1; Gaussian Inc.: Pittsburgh, PA, 2001.

(27) Becke, A. D. J. Chem. Phys. 1993, 98, 5648. Burke, K.; Perdew, J. P.; Wang, Y. In Electronic Density Functional Theory: Recent Progress and New Directions; Dobson, J. F., Vignale, G., Das, M. P., Eds.; Plenum: New York, 1998

(28) Hay, P. J.; Wadt, W. R. J. Chem. Phys. 1985, 82, 270. 
(29) Pyykkö, P.; Mendizabal, F. Inorg. Chem. 1998, 37, 3018.

(30) Couty, M.; Hall, M. B. J. Comput. Chem. 1996, 17, 1359.

(31) Tomasi, J.; Mennucci, B.; Cammi, R. Chem. Rev. 2005, 105, 2999.

(32) Peng, C.; Schlegel, H. B. Isr. J. Chem. 1993, 33, 449. Peng, C.; Ayala, P. Y.; Schlegel, H. B.; Frisch, M. J. J. Comput. Chem. 1995, 16 , 49.

(33) Korgaonkar, A. V.; Gopalaraman, C. P.; Rohatgi, V. K. Int. J. Mass. Spec. Ion Phys. 1981, 40, 127.

(34) Eliav, E.; Kaldor, U.; Ishikawa, Y. Phys. Rev. A 1994, 49, 1724

(35) Bartlett, R. J.; Stanton, J. F. Rev. Comput. Chem. 1995, 5, 65.

Crawford, T. D.; Schaefer, H. F., III. Rev. Comput. Chem. 2000, 14, 33.

(36) For more sophisticated approaches to the issue of calculating the redox potentials and solvation spheres of metal ions, see, for example: Uudsemaa, M.; Tamm, T. J. Phys. Chem. A 2003, 107, 9997. Baik, M.-H.; Freisner, R. A. J. Phys. Chem. A 2002, 106, 7407. Li, J.; Fisher, C. L.; Chen, J.; Bashford, D.; Noodleman, L. Inorg. Chem. 1996, 35, 4694.

(37) Pyykkö, P. Chem. Rev. 1988, 88, 563.

(38) Hay, P. J.; Wadt, W. R.; Kahn, L. R.; Bobrowicz, F. W. J. Chem. Phys. 1978, 69, 984.
(39) Parr, R. G.; Yang, W. In Density-functional Theory of Atoms and Molecules; Oxford University Press: Oxford, 1989.

(40) Weinhold, F.; Landis, C. R. Chem. Ed.: Res. Practice Eur. 2001, 2,91

(41) The feasibility of a triplet transition state for associative disproportionation cannot be conclusively dismissed. The triplet energy at the singlet transition state geometry is only a few $\mathrm{kcal} / \mathrm{mol}$ higher than the singlet. Attempts to geometry optimize a triplet transition state geometry were, however, unsuccessful. Spin-forbidden reactions are expected to be facile due to the large spin-orbit coupling constant of gold $\left(\xi_{5 \mathrm{~d}} \sim 5100\right.$ $\mathrm{cm}^{-1}$; see: Griffith, J. S. Theory of Transition Metal Ions; Cambridge University Press: Cambridge, 1964)

(42) Using the B3PW91/LANL2DZ(2f, d) level of theory, spin density on gold in bis(maleonitriledithiolato)-gold(II) dianion is calculated to be $18 \%$ by a Mulliken population analysis and $13 \%$ by a natural bond orbital analysis. Schlupp and Maki11 determine a value of $15 \%$ from an analysis of EPR spectra of magnetically dilute samples.

(43) Correlation was likewise poor with the ionization potential calculated directly for the reaction: ${ }^{1}$ ligand $\rightarrow{ }^{2}$ ligand $^{+}$. 